anatomy of, say, a member of each of the families of the Lorisidae and Lemuridae rather than spread himself thinly over the whole field. It is to be hoped that any subsequent volumes on the Primates which Dr. Hill may produce will improve on, as well as perpetuate the good points of, the present volume

S. ZUCKERMAN

"See Thomson, J. Oliver, "History of Ancient Geography" (1948

\section{POLYCYCLIC NITROGEN HETEROCYCLES}

Heterocyclic Compounds

Edited by Robert C. Elderfield. Vol. 3 : Polycyclic Derivatives of Pyrrole; Polycyclic Systems with One Nitrogen Common to Both Rings; Pyrindine and related Compounds. Pp. vii +442. 96s. net. Vol. 4 : Quinoline, Isoquinoline and their Benzo Derivatives. Pp. vii +674. 136s. net. (New York : John Wiley and Sons, Inc.; London : Chapman and Hall, Ltd., 1952.)

$\mathrm{T}$

HE ambitious scheme to produce a modern treatise on the chemistry of heterocyclic compounds has made considerable headway with the appearance of these two volumes. They will probably have an even wider appeal than Vols. 1 and 2 (see Nature, 168, 618 ; 1951), for as Prof. R. C. Elderfield says in his preface to Vol. 3, "the chemistry of the polycyclic nitrogen heterocycles containing one hetero nitrogen atom has probably been the object of more intense investigation than any other single group in the broad field of heterocyclic chemistry". It is with these polycyclic nitrogen compounds that Vols. 3 and 4 are concerned. The major part of Vol. 3 (274 pages) is devoted to a most timely and interesting chapter on indole and its derivatives by P. L. Julian and two collaborators. Prof. Elderfield's contribution is far from being restricted to editorial duties. He has himself written the 343-page chapter on quinoline (Vol, 4), and is part author of the chapters on isoindole and on pyrindine, quinindine and their derivatives (Vol. 3). A chapter by H. R. Ing on bicyclic systems with a nitrogen atom common to both rings completes Vol. 3, and Vol. 4 contains also chapters on isoquinoline (Walter $J$. Gensler), the acridines (Adrien Albert), and phenanthridine and benzoquinolines (L. P. Walls). The names of the authors are a sufficient assurance of the authoritative character of the work. So vast a field of organic chemistry as heterocyclic compounds can be surveyed with authority only by a multiplicity of authors, and it is inevitable, therefore, that there should be a certain lack of uniformity in treatment.

Comprehensiveness is not claimed. In particular, there is no detailed treatment of the considerable groups of alkaloids which are derived from the ring systems dealt with in the volumes under review. This omission is entirely justifiable. There are other excellent modern works dealing with alkaloids, and their inclusion in the present work would have made it unwieldy, besides unduly delaying its progress. Although alkaloids are not dealt with systematically, there is incidental reference to many of them; for example, in connexion with quinuclidine, pyrrocoline and pyridocoline, isoquinoline and phenanthridine.

The chapter on indoles gives a survey of numerous methods for their synthesis and a discussion of the mechanism of some of the reactions involved. There is a description of the preparation of various classes of indole derivatives, mostly those substituted in the pyrrole ring. Natural indole derivatives are discussed, including heteroauxine, gramine and tryptophan, and there is a valuable discussion of the metabolism of tryptophan. It would have been useful to have had also a section giving a general account of the properties and reactions of indole and its simple derivatives, although doubtless most of the information which could have been introduced in such a section is scattered through the chapter in its present form.

Reference is made in the prefaces to delays at the proof stage and to the fact that it has not been possible to bring the subject-matter completely up to date. Although unfortunate, this is doubtless unavoidable, especially in fields such as those covered by the present volumes, where new developments are constantly taking place. The section on the stereochemistry of the tropane group, for example, would have been presented rather differently if it had been possible to include the recent work of Prof. G. Fodor.

The books are well printed and produced and scarcely any misprints have been noticed. The numbering of the acridine ring has given some difficulty, and it is interesting to note that the editor has not felt bound to adopt current American practice. Both he and his collaborators are to be congratulated on a most valuable contribution to the literature of organic chemistry. J. W. Cook

\section{A FRESH APPROACH TO INTERMEDIATE BOTANY}

Intermediate Botany

By L. J. F. Brimble. Fourth edition entirely revised and rewritten in collaboration with Dr. S. Williams, and with the assistance of Dr. G. Bond. Pp. $x+$ 505. (London: Macmillan and Co., Ltd., 1953.) $20 s$. net.

TTHE authors have rewritten "Intermediate

Botany" by L. J. F. Brimble and brought it up to date. They have set out to provide a book suitable for candidates for the General Certificate of Education (Advanced Level) and for candidates for first-year university examinations such as those for intermediate science, arts, pharmacy, agriculture, horticulture and medicine. They were obviously faced with various fundamental decisions, and they can scarcely be expected to have produced a volume that is beyond criticism by teachers in at least some of the wide fields for which they have attempted to cater. For example, there will always be two schools of thought as to whether one should begin the session with Pleurococcus or with a whole plant of groundsel. The authors have in some ways chosen the best of both worlds, because they have devoted the first thirty pages or so to an interesting introduction in which they review the subject of botany and the plant kingdom as a whole. Then, when they start the real work they throw in their lot with the groundsel school, except that they use rosebay willowherb for variety.

In the next three hundred pages (approximately) the Angiosperm is treated very fully. The physiology and anatomy are both well presented in the text though the diagrams vary in quality. For example, on p. 253 the stamens of the buttercup are not shown to be extrorse ; part of the diagram of meiosis on 